\title{
Spontaneous Regression of Hepatic Diffuse Large B-cell Lymphoma in HIV and HCV Positive Patient: A Novel Case Study
}

\author{
Albert Alhatem ${ }^{1^{*}}$, Saiaditya Badeti ${ }^{1}$, Chen Liu ${ }^{1,2,3,4}$, Dongfang Liu ${ }^{1,2,3}$ and Donghong Cai ${ }^{1,5}$ \\ ${ }^{1}$ Department of Pathology, Immunology and Laboratory Medicine, Rutgers University, New Jersey Medical \\ School, Newark, NJ, USA \\ ${ }^{2}$ Department of Medicine, Rutgers New Jersey Medical School, Newark, NJ, USA \\ ${ }^{3}$ Rutgers Cancer Institute of New Jersey, Newark, NJ, USA \\ ${ }^{4}$ Department of Pathology, Immunology and Laboratory Medicine, Robert Wood Johnson, New Brunswick, \\ NJ, USA
}

${ }^{5}$ Department of Pathology and Laboratory Medicine, Veterans Affairs New Jersey Health Care System, East Orange, NJ, USA

*Corresponding author: Albert Alhatem, MD, Department of Pathology, Immunology and Laboratory Medicine Rutgers New Jersey Medical School, 150 Bergen St, Room E163A, Newark, NJ 0713, USA

\begin{abstract}
Objective/Background: Diffuse large B-cell lymphoma (DLBCL) rarely occurs in the liver. Spontaneous regression of this tumor is extremely rare. We are reporting the first case of hepatic DLBCL, and we are reviewing the English literature for cases of spontaneous regression of DLBCL and cancer in general.
\end{abstract}

Methods: A 60-year-old gentleman with a history of HIV and $\mathrm{HCV}$ infections presented with an incidental liver mass. He was diagnosed with DLBCL germinal cell type with high grade features based on the results of pathological/cytogenetics studies. He started HCV and HIV medication but refused lymphoma chemotherapy.

Results: Radiological follow up during a four-year period showed a spontaneous regression of his liver mass to a non-detectable size. Review of the English literature revealed 18 cases of DLBCL spontaneous regression, none of which were found in the liver. Here, two mechanisms are proposed to explain this phenomenon; the immunologic and the genetic.

Conclusion: Chemoimmunotherapy is recommended for all DLBCL patients. However, this case of DLBCL spontaneous regression in an HIV and HCV positive patient offers a rare platform to understand the immune and genetic mechanisms for cancer and lymphoma in particular.

\author{
Keywords \\ Diffuse large B-cell lymphoma, Spontaneous cancer re- \\ gression, Tumor associated antigens, Human Immune De- \\ ficiency Virus
}

\section{Introduction}

The miraculous self-healing of cancer without treatment has fascinated the medical and non-medical community for ages. There are a few case studies in the literature documenting spontaneous regression of malignant tumors [1]. Though these studies offered some explanations for this phenomenon, the mechanisms are still elusive. Therefore, understanding the nature of spontaneous remission in cancer would not only satisfy the curiosity of the mind but could also provide a potential platform to treat cancer patients.

The first reported case of spontaneous cancer regression was in the $14^{\text {th }}$ century [2]. Peregrine Laziosi (1265-1345) was a priest and later became the patron saint of cancer patients. It was reported that he had his bone sarcoma spontaneously healed by divine intervention after a severe bacterial infection [2,3]. In late 1800, William Coley noted that inducing a fever could result

Citation: Alhatem A, Badeti S, Liu C, Liu D, Cai D (2019) Spontaneous Regression of Hepatic Diffuse Large B-cell Lymphoma in HIV and HCV Positive Patient: A Novel Case Study. Int J Cancer Clin Res 6:127. doi. org/10.23937/2378-3419/1410127

Accepted: October 21, 2019; Published: October 23, 2019

Copyright: (C) 2019 Alhatem A, et al. This is an open-access article distributed under the terms of the Creative Commons Attribution License, which permits unrestricted use, distribution, and reproduction in any medium, provided the original author and source are credited. 
in tumor regression, which led him to later develop a bacterial vaccine ("Coley's vaccine") that was successful in reducing tumors in some of his patients [4]. Later in 1956, Everson and Cole, et al. defined the modern version of spontaneous regression of cancer as: "the partial or complete disappearance of a malignant tumor in the absence of all treatment, or in the presence of therapy, which is considered inadequate to exert a significant influence on neoplastic disease [5-7]".

There are a few reports of biopsy-confirmed malignancies that later spontaneously regressed, which include garden variety cancer types and histology. Examples include: Acute myelocytic leukemia, chronic lymphocytic leukemia, Hodgkin's lymphoma, non-Hodgkin's lymphoma, breast cancer, non-small cell and small cell lung cancer, testicular cancer, prostate cancer, cervical cancer, hepatocellular cancer, colon cancer, Merkel cell carcinoma, sarcoma, melanoma, neuroblastoma, astrocytoma, and renal cell carcinoma [8-25]. The frequency of this phenomenon in all cancers has been reported as 1 case per $80,000-100,000$ [25]. While not uncommon in low-grade lymphomas, spontaneous remission in aggressive, high-grade NHL is rare [25].

We present here for the first time a case of a spontaneous remission of liver diffuse large B-cell lymphoma. We also reviewed the literature to seek some explanations for this interesting phenomenon.

\section{Case Presentation}

A 60-year-old male with history of hepatitis $C$ virus (2003) and human immunodeficiency virus (2009) infections presented with an incidental liver mass on ultrasound in 2014. Triple-phase computed tomography (CT) study confirmed a $6 \times 5.3 \times 3 \mathrm{~cm}$ heterogeneously enhancing mass in the right hepatic lobe (Figure 1a and Figure $1 \mathrm{~b}$ ). Borderline enlarged lymph nodes were noted in the base of the right heart and in the right paraoesophageal and IVC junction region, the largest of which measured $1.2 \times 1.3 \mathrm{~cm}$.

CT-guided Liver core biopsy showed diffuse infiltration of large atypical lymphocytes (Figure 2a). Immunohistochemistry showed that the atypical lymphocytes



Figure 1: a,b) Computer Tomography images showing the liver mass obtained in 2014 showing the liver mass at the time of diagnosis.
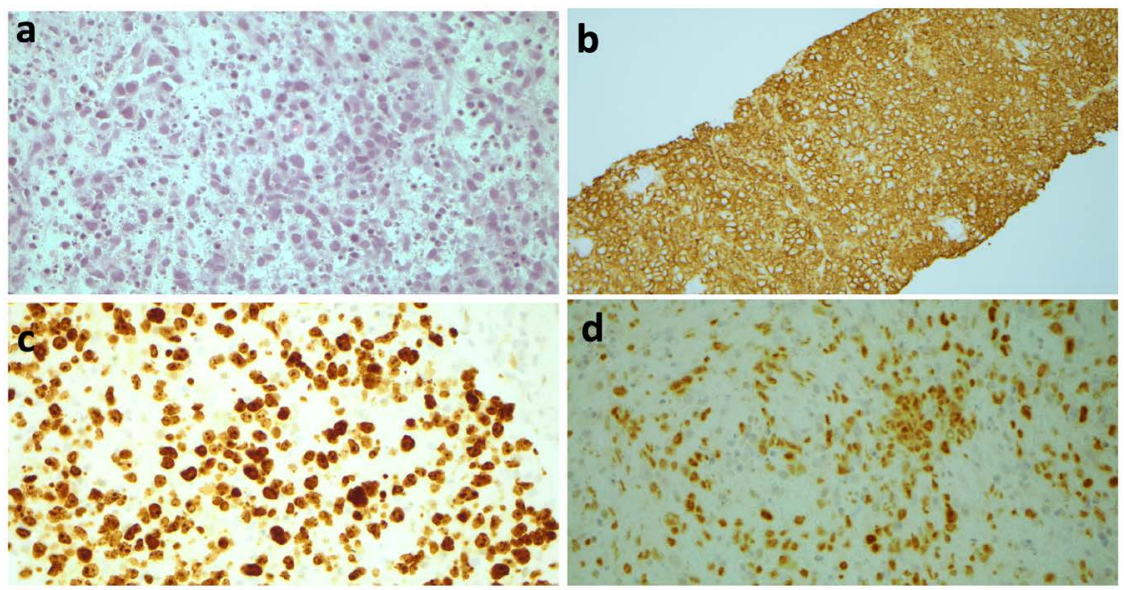

Figure 2: A summary panel of the histopathologic examination of the mass. Hematoxylin and Eosin stain a) Showing large malignant cells with scattered small lymphocytes in the background; b) Immunohistochemical stains for CD20; c) Ki-67; b) Bcl-6 were positive in the malignant cells, CD10 and MUM-1 were negative (not shown), all consistent with diffuse large B-cell lymphoma, germinal center B-cell subtype. 
were positive for $\mathrm{CD} 20$ and $\mathrm{Bcl}-6$ (Figure $2 \mathrm{~b}$ and Figure $2 \mathrm{~d}$ ). They were negative for $\mathrm{Bcl}-2$, MUM-1, CD10, CD30, Cyclin D1, and EBER. CD3, CD5 highlighted a few scattered T-cells and $C D 21$ revealed no dendritic cell meshwork. Ki-67 proliferative index was more than $90 \%$ (Figure 2c). Florescence In-Situ Hybridization study revealed no $B C L 2, B C L 6$, or C-MYC gene rearrangement. The findings were consistent with a DLBCL, germinal center B-cell type, with high grade features. Bone marrow biopsy showed normocellular marrow for age with no evidence of involvement by B-cell lymphoma.

The patient was started on HCV medications and Highly Active Antiretroviral Therapy (HAART) but refused chemotherapy for lymphoma. In 2017, CT showed a poorly heterogenous right peripheral lesion measured $2.6 \mathrm{~cm}$ compared to $6 \mathrm{~cm}$ in greatest dimension in the previous study (2014). There was no evidence of lymphadenopathy. In 2018, CT revealed that the previous liver lesion regressed to $0.9 \mathrm{~cm}$ (Figure $3 a$, and Figure $3 \mathrm{~b}$ ) and disappeared completely in 2019. During all this time period (2014-2019), the patient received no oncological therapy. On his follow up visit his HCV and HIV levels were undetectable.

\section{Discussion}

Spontaneous regression of cancer is rare. For lymphoma cases, one study reported 2 out of 69 diffuse large B-cell lymphoma cases (2.9\%) and 18 out of 140 follicular lymphoma cases (12.9\%) underwent spontaneous remission, including cases with relapsed or stable disease after treatment [26]. Another report found 6 out of 44 cases of low grade lymphomas (13.6\%) without previous treatment showed spontaneous remission [27]. There are some reports in the literature trying to provide explanations for this fascinating phenomenon $[28,29]$, yet the mechanism for which is still largely not well understood. Two mechanisms have been proposed in the literature: The systemic immune response and the genetic mechanism.

\section{Immune response mechanism}

One likely reason for spontaneous regression is that an antitumor immune response from the patient is triggered by either specific antigens expressed on the tumor associated antigens (TAAs), infection, or injury. This field of study was initiated by the work of Lloyd Old, the founder of modern cancer immunology. He observed the phenomenon in studying melanoma histopathology. In regression cases, high numbers of immune cells were often found inside the melanocytic tumor nests. He assumed the tumor cells expressed unique antigens that stimulated the host immune system. He also observed that in one renal cell carcinoma patient with pulmonary metastasis that surgical removal of a part of the tumor resulted in spontaneous regression of the remaining tumor [30]. Again he assumed that the surgery (and the subsequent inflammation) stimulated/ triggered the host immune response and eliminated the rest of the tumor cells. Spontaneous remission has also been frequently observed in patients with concomitant viral infections, such as human immunodeficiency virus and Epstein-Barr virus [31,32]. Interestingly, our patient has HIV and HCV infection, which could serve as a plausible mechanism for regression. The potential mechanisms behind immunologic stimuli inducing remission are many, but a unifying theory involves the immune system gaining the ability to recognize and react to malignant cells which were otherwise able to evade recognition previously. Therefore, any impetus that activates host immunity theoretically enhances the possibility of host recognition of malignant cells.

The immune-editing theory as proposed by Schreiber, Smyth and Old, et al. [33] has refined the understanding of spontaneous regression by positing a process by which cancer cells alter their immunological profile leading to incomplete elimination, equilibrium, and immune escape [30]. Under ideal conditions, the innate and adaptive immunity work in harmony to destroy cancer cells but often imperfectly, thus explaining why

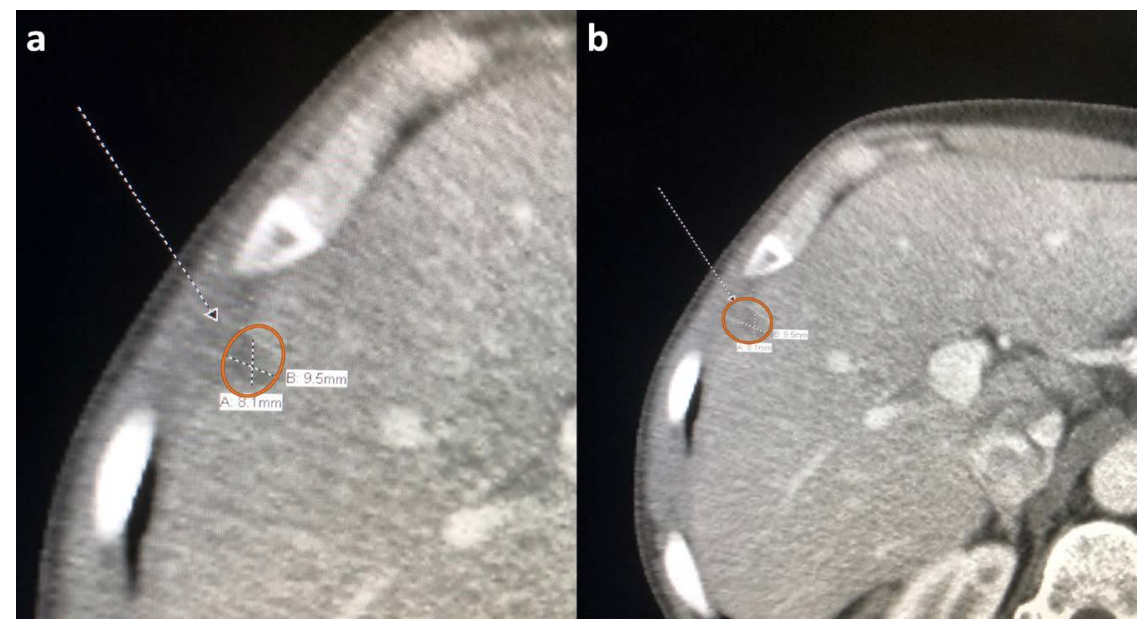

Figure 3: a,b) Computer Tomography images showing the liver mass obtained in 2018 showing the liver mass regression without treatment. 
most spontaneously regressed cancers recur, sometimes even years later. The abscopal (or out-of-field) effect of radiation therapy is another example that supports this observation. It is theorized that the release of tumor associated antigens following radiotherapy causes the immune system to mount a systemic response to distant metastases [34].

Due to its rapid progression, diffuse large B-cell lymphoma (DLBCL), is often deadly without immediate immunochemotherapy [35]. A reduced number of chemotherapy cycles with a local radiation therapy is recommended for patients with localized disease [36]. However, the specific location of the lymphoma and nodal or extranodal status have been proposed as factors for determining the mechanism by which the tumor is regressed. The microenvironment is different between nodal and extranodal tumors. However, this assumption is based on limited information available in the literature as only one nodal case of DLBCL has been reported to have spontaneously regressed compared to the 17 reported extranodal cases of DLBCL [29], with the most common locations being the head and neck [31,37-41], breast [32,42,43], and stomach [44-46]. Other locations include the lumbar spine [47], chest wall [48], and skin [49]. Therefore, it is important to further investigate this concept to shed more light on this area [50]. Furthermore, the physical disruption of the tumor microenvironment has been proposed as the mechanism by which DLBCL regressed as every reported case regressed following a surgical biopsy similar to the renal cell carcinoma case, which is believed to stimulate the immune system to cancer antigens.

Other pieces of evidence that support the immune response mechanism are the presence of fibrosis and small lymphocytes infiltrating the tissue of regressed lymphoma cases [51], the cross-reactivity of pathogen-specific T-cells with tumor antigens [52,53], and nonspecific tumor killing due to natural killer cell activation in response to a viral or bacterial infection $[26,27]$.

\section{Genetic mechanism}

Human genetics are vastly varied, and can influence a tumor's behavior. This could explain why some cancers are aggressive in some people, but spontaneously regress in others. Mutations in some cancers can affect the tumor growth, metastasis, and response to treatment. As such, genetic mutations have been proposed as a mechanism for spontaneous regression. For example, the presence of tropomyosin receptor kinase $A$ (TrkA) cell receptors, hyperdiploidy, and telomerase control dictates whether neuroblastoma regresses spontaneously in children under 18 months (type 1) or displays an aggressive phenotype (type 2 ) with a $40-50 \%$ survival rate in children older than 18 months [54]. Moreover, epigenetic changes can modify the activity of various proteins by changing the behavior of different DNA regions, which leads to the apoptosis of the cancer cells in neuroblastoma $[55,56]$. More research remains to be seen in this area, which could be invaluable in developing new cancer treatment strategies.

\section{Conclusions}

In summary, we presented here for the first time a case of spontaneous remission of DLBCL in the liver. Because it is a rare phenomenon with few documented cases, the mechanism by which this remission occurred is not well understood. Though it is obviously recommended to provide all DLBCL patients with chemoimmunotherapy as soon as they are diagnosed, having rare cases with spontaneous tumor regression may shed light on the pathogenesis and treatment of lymphoma and cancer in general. In our patient, having concomitant viral infections (HIV and HCV), could be categorized as an immune system gain of function to recognize and react to malignant cells as previously described in Ogawa, et al. [44] and Machida, et al. [48] Understanding the immune and genetic mechanisms of these spontaneous remissions could lead to the establishment of new animal models, and the development of new therapeutic strategies for the treatment of cancer.

\section{Acknowledgment}

None.

\section{Declaration of Conflicting Interests}

The author(s) declared no potential conflicts of interest with respect to the research, authorship, and/or publication of this article.

\section{Funding}

The author(s) received no financial support for the research, authorship, and/or publication of this article.

\section{References}

1. Krone B, Kolmel KF, Grange JM (2014) The biography of the immune system and the control of cancer: from St Peregrine to contemporary vaccination strategies. BMC Cancer 14: 595.

2. Jackson R (1974) Saint Peregrine, OSM--the patron saint of cancer patients. Can Med Assoc J 111: 824-827.

3. Pack GT (1967) St. Peregrine, OSM--the patron saint of cancer patients. CA Cancer J Clin 17: 181-182.

4. Coley WB (1910) The Treatment of Inoperable Sarcoma by Bacterial Toxins (the Mixed Toxins of the Streptococcus erysipelas and the Bacillus prodigiosus). Proc R Soc Med 3: 1-48.

5. Rohdenburg GL (1918) Fluctuations in the Growth Energy of Malignant Tumors in Man, with Especial Reference to Spontaneous Recession. Cancer Research 193.

6. Morton JJ Jr, Morton JH (1953) Cancer as a chronic disease. Ann Surg 137: 683-703.

7. Cole WH, Everson TC (1956) Spontaneous regression of cancer: Preliminary report. Ann Surg 144: 366-383. 
8. Barrett R, Morash B, Roback D, Pambrun C, Marfleet L, et al. (2017) FISH identifies a KAT6A/CREBBP fusion caused by a cryptic insertional $t(8 ; 16)$ in a case of spontaneously remitting congenital acute myeloid leukemia with a normal karyotype. Pediatr Blood Cancer 64.

9. D'Arena G, Guariglia R, Pietrantuono G, Villani O, Martorelli MC, et al. (2014) More on spontaneous regression of chronic lymphocytic leukemia: two new cases and potential role of lamivudine in a further patient with advanced disease and hepatitis B virus infection. Leuk Lymphoma 55: 1955-1957.

10. Udupa K, Philip A, Rajendranath R, Sagar T, Majhi U (2013) Spontaneous regression of primary progressive Hodgkin's lymphoma in a pediatric patient: A case report and review of literature. Hematol Oncol Stem Cell Ther 6: 112-116.

11. Takahashi T, Ikejiri F, Takami S, Okada T, Kumanomidou S, et al. (2015) Spontaneous Regression of Intravascular Large B-Cell Lymphoma and Apoptosis of Lymphoma Cells: A Case Report. J Clin Exp Hematop 55: 151-156.

12. Ito E, Nakano S, Otsuka M, Mibu A, Karikomi M, et al. (2016) Spontaneous breast cancer remission: A case report. Int J Surg Case Rep 25: 132-136.

13. Nakamura $Y$, Noguchi $Y$, Satoh E, Uenaka A, Sato $S$, et al. (2009) Spontaneous remission of a non-small cell lung cancer possibly caused by anti-NY-ESO-1 immunity. Lung Cancer 65: 119-122.

14. Kitai H, Sakakibara-Konishi J, Oizumi S, Hirohashi Y, Saito W, et al. (2015) Spontaneous regression of small cell lung cancer combined with cancer associated retinopathy. Lung Cancer 87: 73-76.

15. Balzer BL, Ulbright TM (2006) Spontaneous regression of testicular germ cell tumors: an analysis of 42 cases. Am J Surg Pathol 30: 858-865.

16. Lee T, Guo Y, Vij S, Bansal R, Wong NC, et al. (2017) Case: Spontaneous regression of post-radical prostatectomy prostate-specific antigen elevation without adjuvant therapy in a patient with lymph node metastasis. Can Urol Assoc J 11: E315-E317.

17. Katano A, Takenaka R, Okuma K, Yamashita H, Nakagawa K (2015) Repeated episodes of spontaneous regression/progression of cervical adenocarcinoma after adjuvant chemoradiation therapy: A case report. J Med Case Rep 9: 114.

18. Parks AL, McWhirter RM, Evason K, Kelley RK (2015) Cases of spontaneous tumor regression in hepatobiliary cancers: Implications for immunotherapy? J Gastrointest Cancer 46: 161-165.

19. Chida K, Nakanishi K, Shomura H, Homma S, Hattori A et al. (2017) Spontaneous regression of transverse colon cancer: a case report. Surg Case Rep 3: 65.

20. Pang C, Sharma D, Sankar T (2015) Spontaneous regression of Merkel cell carcinoma: A case report and review of the literature. Int J Surg Case Rep 7C: 104-108.

21. Bonvalot S, Ternes N, Fiore M, Bitsakou G, Colombo C, et al. (2013) Spontaneous regression of primary abdominal wall desmoid tumors: more common than previously thought. Ann Surg Oncol 20: 4096-4102.

22. Miller CV, Cook IS, Jayaramachandran R, Tyers AG (2014) Spontaneous regression of a conjunctival malignant melanoma. Orbit 33: 139-141.

23. Diede SJ (2014) Spontaneous regression of metastatic cancer: learning from neuroblastoma. Nat Rev Cancer 14:
71-72.

24. Buder T, Deutsch A, Klink B, Voss-Bohme A (2015) Model-Based Evaluation of Spontaneous Tumor Regression in Pilocytic Astrocytoma. PLoS Comput Biol 11: e1004662.

25. Murphy KA, James BR, Guan Y, Torry DS, Wilber A, et al. (2015) Exploiting natural anti-tumor immunity for metastatic renal cell carcinoma. Hum Vaccin Immunother 11: 16121620.

26. Roda JM, Parihar R, Lehman A, Mani A, Tridandapani S, et al. (2006) Interleukin-21 enhances NK cell activation in response to antibody-coated targets. J Immunol 177: 120-129.

27. Ma J, Ma D, Ji C (2011) The role of IL-21 in hematological malignancies. Cytokine 56: 133-139.

28. Potts DA, Fromm JR, Gopal AK, Cassaday RD (2017) Spontaneous Remission of an Untreated, MYC and BCL2 Coexpressing, High-Grade B-Cell Lymphoma: A Case Report and Literature Review. Case Rep Hematol 2017.

29. Buckner TW, Dunphy C, Fedoriw YD, van Deventer HW, Foster MC, et al. (2012) Complete spontaneous remission of diffuse large B-cell lymphoma of the maxillary sinus after concurrent infections. Clin Lymphoma Myeloma Leuk 12: 455-458.

30. O'Sullivan T, Dunn GP, Lacoursiere DY, Schreiber RD, Bui JD (2011) Cancer immunoediting of the NK group 2D ligand H60a. J Immunol 187: 3538-3545.

31. Tamas L, Sari E, Repassy G, Szabo P, Bagdi E, et al. (2011) Spontaneous remission in localized diffuse large B-cell lymphoma. Pathol Oncol Res 17: 779-784.

32. Iwatani T, Kawabata H, Miura D, Ota Y, Ohashi K (2011) Complete spontaneous regression of primary diffuse large B-cell lymphoma of the breast. J Clin Oncol 29: e113-e115.

33. Schreiber RD, Old LJ, Smyth MJ (2011) Cancer immunoediting: integrating immunity's roles in cancer suppression and promotion. Science 331: 1565-1570.

34. Cong Y, Shen G, Wu S, Hao R (2017) Abscopal regression following SABR for non-small-cell-lung cancer: A case report. Cancer Biol Ther 18: 1-3.

35. Coiffier B (2003) Immunochemotherapy: the new standard in aggressive non-Hodgkin's lymphoma in the elderly. Semin Oncol 30: 21-27.

36. Persky DO, Unger JM, Spier CM, Stea B, LeBlanc M, et al. (2008) Phase II study of rituximab plus three cycles of CHOP and involved-field radiotherapy for patients with limited-stage aggressive B-cell lymphoma: Southwest Oncology Group study 0014. J Clin Oncol 26: 2258-2263.

37. Koga M, Kusukawa J, Hayabuchi N (2003) Spontaneous regression of extranodal malignant lymphoma occurred in the gingiva. Oral Oncol 39: 323-324.

38. Heibel $H$, Knodgen $R$, Bredenfeld $H$, Wickenhauser $C$, Scheer M, et al. (2004) Complete spontaneous remission of an aggressive non-Hodgkin's lymphoma with primary manifestation in the oral cavity. Leuk Lymphoma 45: 171-174.

39. Chang YC, Chang CH, Liu YT, Tsai KB, Liu TC, et al. (2004) Spontaneous regression of a large-cell lymphoma in the conjunctiva and orbit. Ophthalmic Plast Reconstr Surg 20: 461-463.

40. McCabe MG, Hook CE, Burke GA (2008) Spontaneous regression of an EBV-associated monoclonal large B cell proliferation in the mastoid of a young child following surgical biopsy. Pediatr Blood Cancer 51: 557-559.

41. Brachet $P$, de Leval L, Chantrain G, Loeb I, Saussez S 
(2011) Hard palate B cell lymphoma with spontaneous regression. Rev Stomatol Chir Maxillofac 112: 180-182.

42. lihara K, Yamaguchi K, Nishimura Y, Iwasaki T, Suzuki K, et al. (2004) Spontaneous regression of malignant lymphoma of the breast. Pathol Int 54: 537-542.

43. Oya M, Hirahashi M, Ochi M, Hashimoto M, Ohshima K, Kikuchi M, et al. (2009) Spontaneous regression of primary breast lymphoma. Pathol Int 59: 664-669.

44. Ogawa D, Uemura N, Sasaki N, Mukai T, Yamaguchi S, et al. (1998) Spontaneous regression of malignant lymphoma of the stomach. J Med 29: 381-393.

45. Ogata M, Kikuchi H, Ono K, Ohtsuka E, Gamachi A, et al. (2004) Spontaneous remission of Epstein-Barr virus-negative non-Hodgkin's lymphoma after withdrawal of cyclosporine in a patient with refractory anemia. Int $\mathrm{J}$ Hematol 79: 161-164.

46. Watari J, Saitoh Y, Fujiya M, Nakamura K, Inaba Y, et al. (2005) Spontaneous remission of primary diffuse large B-cell gastric lymphoma. J Gastroenterol 40: 414-420.

47. Ohgi S, Ehara S, Satoh T, Kato S, Shimosegawa K, et al. (2002) Spontaneous regression of malignant lymphoma of the lumbar spine. Skeletal Radiol 31: 99-102.

48. Machida K, Inoue Y, Honda N, Hosono M, Takahashi T, et al. (2003) Spontaneous regression of chest wall malignant lymphoma. Presentation on Ga-67 imaging. Clin Nucl Med 28: 405-407.

49. Lim Z, Cassells R, Giles A, Cheow HK, Mir N (2007) Dif- fuse large B-cell lymphoma developing following treatment of Waldenstrom's macroglobulinaemia: spontaneous resolution upon cessation of fludarabine. Leuk Lymphoma 48: 1638-1640.

50. Coupland SE (2011) The challenge of the microenvironment in B-cell lymphomas. Histopathology 58: 69-80.

51. Starnes CO (1992) Coley's toxins in perspective. Nature 357: 11-12.

52. Burrows SR, Silins SL, Khanna R, Burrows JM, Rischmueller M, et al. (1997) Cross-reactive memory T cells for Epstein-Barr virus augment the alloresponse to common human leukocyte antigens: degenerate recognition of major histocompatibility complex-bound peptide by $T$ cells and its role in alloreactivity. Eur J Immunol 27: 1726-1736.

53. D'Orsogna LJ, Amir AL, Zoet YM, van der Meer-Prins PM, van der Slik AR, et al. (2009) New tools to monitor the impact of viral infection on the alloreactive T-cell repertoire. Tissue Antigens 74: 290-297.

54. Brodeur GM, Bagatell R (2014) Mechanisms of neuroblastoma regression. Nat Rev Clin Oncol 11: 704-713.

55. Barbieri E, De Preter K, Capasso M, Chen Z, Hsu DM, et al (2014) Histone chaperone CHAF1A inhibits differentiation and promotes aggressive neuroblastoma. Cancer Res 74: 765-774.

56. Decock A, Ongenaert $M$, Vandesompele J, Speleman $F$ (2011) Neuroblastoma epigenetics: from candidate gene approaches to genome-wide screenings. Epigenetics 6: 962-970. 